\title{
Assessment of technological preparedness coal deposits to a rational industrial development
}

\author{
Marina Pisarenko ${ }^{1^{*}}$ \\ ${ }^{1}$ Federal Research Center for Coal and Coal Chemistry Of the Siberian Branch, Russian Academy of \\ Sciences, Kemerovo, Russia.
}

\begin{abstract}
In order to ensure the rationality, saving of mineral resources and to encourage subsoil users to improve production and processing technologies, it is proposed to involve deposits estimated as technologically prepared in the industrial development. This assessment, which is understood to be the compliance of industrial production technologies with mining and geological conditions of the deposits, is proposed to be included in the geological materials for the development of the deposits. As an indicator of determining the technological readiness of the site, use the coefficient of technological readiness-the ratio of the volume of outside-balance resource to the total geological reserves.
\end{abstract}

\section{Introduction}

The Kuznetsk coal basin is one of the largest basins in the world, with resources up to a depth of $600 \mathrm{~m}$ estimated at 218 billion tons, and balance reserves as of 01.01 .2014 are 68 billion tons against the background of the favorable global coal market, the volume of production in the basin is growing. Thus, the results of 2017 production in Kuzbass amounted to 241.2 million tons - this is $59 \%$ of the total Russian production, and increased by 1.67 times compared to 1990 (the maximum achieved volume before the restructuring of the coal industry).

The mineral resource base of the Kuznetsk coal basin is represented by coal deposits with a wide variety of mining and geological development conditions, which includes the entire range of geological and technological features, which makes it possible to consider the basin as a testing ground for testing technologies various mining and processing. However, despite a wide range of mining and geological conditions, the existing technological policy of basin development is oriented to an extensive way and consists in using a limited set of coal mining technologies. Thus, the transport system mining with the use of motor transport for the transportation of coal and overburden (about $93 \%$ of open-pit coal mining), which is acceptable for a wide range of mining and geological conditions, but is the most costly.

\footnotetext{
* Corresponding author: iu.kemsc@mai.ru
} 
A longwall mining with smooth roof lowering carries out coal mining by underground method. The economic efficiency of such technological structures is determined by the productivity of the mining face and is achieved with an annual mining of more than 1.0 million tons, which is only possible in favorable mining and geological conditions and at optimum sizes of mine fields: with of length cross-pitch mining $3.0 \mathrm{~km}$, lava from $230 \mathrm{~m}$, of thickness of coal seams is more than $2 \mathrm{~m}$ and of angles of incidence of layers to $20^{\circ}$, disjunctive disturbance up to $50 \mathrm{~m} / \mathrm{ha}$, gas content of coal seams up to $10 \mathrm{~m} 3 / \mathrm{t}$ [], etc.

The implemented extensive way of development of mineral resources, aimed at search and development of reserves of sites with a given favorable mining and geological conditions, significantly reduces the mineral potential of Kuzbass (in the extraction of $1 \mathrm{t}$ of coal about $3 \mathrm{t}$ of proven reserves are written off the balance sheet) and does not fully meet the requirements of safety and rationality of subsoil use []. At the same time, the technological platform of coal geotechnologies [] contains a number of promising technologies that, when adapted to specific mining and geological conditions of the sites and improved, will allow to work out powerful and thin layers of inclined and steep deposits, converting outside-balance resource into balance reserves. However, the transition to an intensive path of development of the mineral and raw materials base requires the development of a set of measures, including legislative ones, aimed at encouraging subsoil users to more fully extraction reserves of deposits.

\section{Theory}

The legal basis for the beginning of the development of the subsoil area by the mining business is the obtaining of a license for the subsoil use. In fact, the license holder receives a legally formalized right to physical destruction of the non - renewable natural resource.

The right of the state as the owner of the subsoil is realized through the state expertise of geological information and project documentation the development of the deposit, their coordination and approval. Based on the results of the state expertise of the feasibility study of the parameters for the calculation of reserves, all the geological reserves of the field are divided according to their industrial importance into balance reserves and outside-balance resource, based on the current capabilities of mining technologies and the economy of mineral raw materials. After the calculation of reserves and their approval, the subsoil user proceeds to the development of the subsoil development project, which focuses on the rational development of only balance reserves, since their development ensures return on investment and profit. The task of preserving outside-balance resource before the subsoil user is not set, although on many of deposits the share of outside-balance resource that do not meet the requirements of the production technologies used is very significant. So, for example, share of outside-balance resource it exceeded $30 \%$ in the boundaries of the Ulyanovskaya mine, around $50 \%$ on Kolmogorovsky-3 mine, etc. At the same time, share of outside-balance resource reserves are a raw material potential that can be transformed into a real raw material base as a result of improved mining and processing technologies in the foreseeable future. Since in accordance with article 35 Of the law of the Russian Federation "on subsoil" the main task of state regulation of subsoil use relations is the rational use of mineral resources in the interests of current and future generations of the peoples of the Russian Federation, the protection of share of outside-balance resource is a function of the state.

The implementation of this function involves the assessment of the importance of outside-balance resource, the number of which ultimately determines the compliance of 
technologies of mining the geologicals conditions of deposit, i.e. the technological readiness of the field (site) for mining coal. As an indicator, the value of which determines the technological readiness, the coefficient of technological readiness is proposed. The value of the coefficient is determined share of outside-balance resource in of geological resources. If the value of the coefficient is more than acceptable, the deposit is not technologically ready for mining coal.

The boundary value of the coefficient of technological readiness in addition to mining and geological and mining conditions, depends of economics of mineral raw materials, socio-economic, infrastructure features of the site and requires additional research. As a first approximation for coal deposits, it is proposed to adopt a standard of $20 \%$ as a basis. This standard is adopted by analogy with the regulated current document [], according to which the recalculation and re-approval of reserves are made if the share of reserves not subject to development in the total reserves exceeds $20 \%$. In addition, as shown by the analysis of project documents for the last 5 years, a decrease in the volume of recoverable reserves by $20 \%$ reduces net discounted income (NPV) by an average of $70-80 \%$ and such a decrease in reserves is significant for the mining investment project.

Reliable calculation of outside-balance resource involves the correct determination of the parameters of their conditions. The procedure for determining the boundary that separates the balance reserves from outside-balance resource is generally recognized and implemented in the current methodology for the feasibility study of conditions. However, their other (bottom) boundary cannot be established in the same way, therefore are accepted the parameters established by the decision of the Commission of the USSR state planning Committee of July 13, 1960 adopted more than half a century ago. Since their adoption, there have been significant changes in the technology of mining and the economy of mineral raw materials.

The system analysis of 12 and 10 non-traditional technologies of coal mining, respectively, by underground and open-pit methods, which have passed industrial and semiindustrial testing and have the signs of promising technologies, allowed to establish the areas of their use. In accordance with this, it is recommended to take seam thickness the of more than $0.4 \mathrm{~m}$ as the "lower" boundary for calculating outside-balance resource of energy coals and coking coals.

The system analysis of coal processing technologies showed that there are no technological restrictions on the ash content of the raw materials supplied for enrichment, and they are determined only by the economy. A series of simplified economic calculations for the complex " the mining and processing" on conventionally grouped by price technological brands of coal allowed to clarify the maximum values of ash content of coal for the calculation of outside-balance resource (fig. 1).

According to studies, the recommended ash content of the coal seam for the calculation of outside-balance resource of technological brands coal: $1-\langle\mathrm{K}, \mathrm{КЖ,} \mathrm{Ж,} \mathrm{ГЖ»} \mathrm{is} 59-67 \%$; 2-«ТС»-53-63 \%;3- «КСН, КС, КО»-43- 55\%; 4-«А, Т, СС, Г»- 42-55\%; 5 - «Д, ДГ» $-30-45 \%$. The upper value in this range refers to the coals of light degrees of washability, the lower value in this range refers of very difficult degree of washability. It should be noted that these ash values are obtained by at the accepted price of coal, according to the price list № 003-01-01 and the average costs for the dressing of the rock mass which using in the mining projects.

According to the adopted provision, the technologically prepared deposit is the most of the reserves of which will be extracted as a result of the implementation of design decisions. Since coal deposits are includes from 3 to 20 seams of coal, the capacity and quality characteristics of which vary in the subsoil space, it is necessary distinguish technologically prepared areas within a large field. To do this, build a mining-geometric 
model in which the simulated indicator is the coefficient of technological readiness. This model to display the spatial variability of the share of reserves left in the subsoil as the toposurface.

As an information basis for the construction of models of technological readiness it is proposed to use of calculation the seams plans of reserves. The method of construction of such models is described in detail in []. In Fig.2 the constructed model is presented of the real mining area (the name of which is not given for the reasons of preserving the commercial secrets of the subsoil user). A feature of this mining area is that the productive thickness before horizon $-100 \mathrm{~m}$ (abs.) includes 10 coal seams of technological brands coal "Д, ДГ", the average power of which varies from 0.75 to $7.07 \mathrm{~m}$.

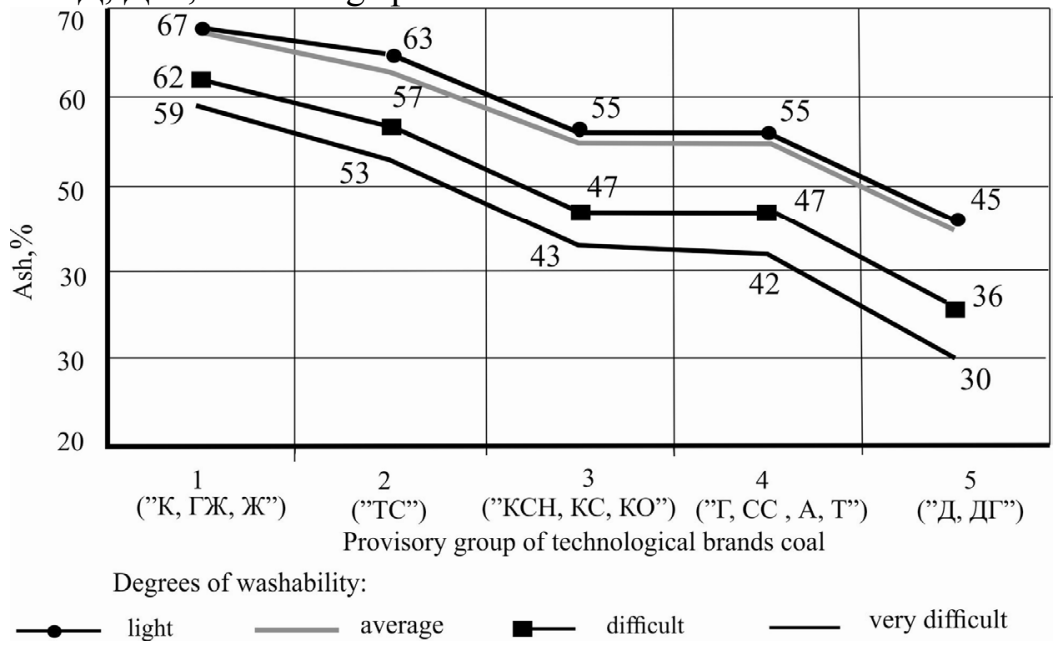

Fig. 1. Maximum ash content of coal for off-balance reserves calculation.

The calculation of balance reserves was carried out according to the parameters of the conditions that meet the requirements of the adopted production technology for the site, namely the longwall (long-pillar) mining with the equipment of the treatment face with a mechanized complex (minimum seam coal of $1.8 \mathrm{~m}$ and maximum ash content of coal 35 $\%)$.

When calculating outside-balance resource, the following parameters are used - the minimum seam coal of $0.4 \mathrm{~m}$ and the maximum ash content of coal is $45 \%$.

Since within the boundaries of the analyzed area only four of the ten coal seams have a capacity of more than $1.8 \mathrm{~m}$, and the remaining six layers do not meet the requirements of the adopted technology, the coefficient of technological readiness of the deposit is about $0.45-0.6$, which is higher than the boundary value, i.e. the deposit is technologically not prepared. This conclusion is confirmed by the practice of mining in this deposit.

During the operation of the coal mining enterprise, mining was carried out on two upper seams. The seam thickness more than $4.8 \mathrm{~m}$ was mininged with loss of layer of coal and was about $3.8 \mathrm{~m}$. In addition, after the mining of the upper seams, the subsoil user decided not to work out the underlying seams with thickness of about $1.8 \mathrm{~m}$ for economic reasons. As a result, only about $17 \%$ of the reserves was mining.

The company is currently closed. The coal reserves contained in the a seam thickness of less than $1.8 \mathrm{~m}$, in the amount of 50 million tons, was transferred to the state balance, and their mining in the near future is unlikely. 


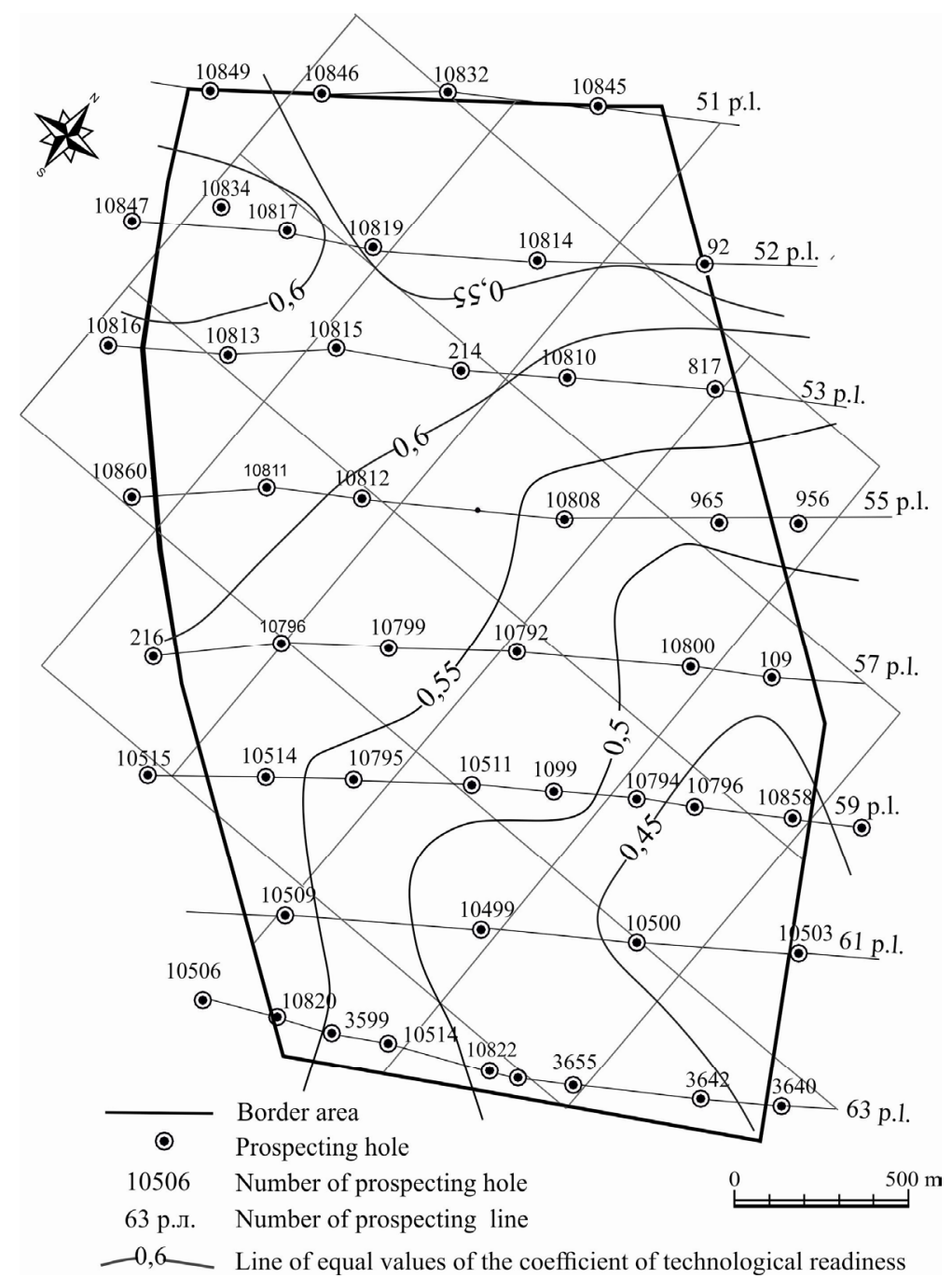

Fig. 2. Toposurface of technologically prepared areas before horizon $-100 \mathrm{~m}$ (abs.).

\section{Conclusion}

For to ensure rational development of mineral resources and to stimulate the subsoil to the development and improvement of technologies of mining and processing the current assessment of the preparedness of deposits for industrial mining added by the assessment of technological readiness of the site. It is proposed to carry out this assessment during the state examination of geological materials, and the presence of a positive assessment is the legal basis for the development of technological projects for the mining of deposits. 


\section{References}

1. S. Shaklein , M. Pisarenko. Mineral resource or Russia. Economics \& Management. 5, P. 25-29. (2010).

2. S. Shaklein , M. Pisarenko. JMS. 50 (3). P. $527-532$ (2014)

3. M. Pisarenko.. Subsoil use of the XXI century 5, P. 106-110 (2015)

4. V.Yakovlev., G. Karmaev., V.Bersenev, A. Glebov, A. Semenkin, I.Sumina. JMS. 52 (1). P. 7 (2016).

5. A. Netsvetaev, A. Grigoryan, D. Prugina. UGOL 1, P. 25-29. (2015).

6. E. Kreinin. UGOL. 7. P. 58-59. (2006).

7. I. Mohnachuk,, B. Myshlyaev, S. Titov. UGOL 9, P. 15-17. (2013).

8. H. Foss., M. Bittner. Gluckauf. 6, p. 139. (2003).

9. V. Klishin., S. .Klishin. JMS. 46 (2). P. 149-159. (2010).

10. S. Shemyakin, D. Matveev, A. Cheban. Gornyi Zhurnal. 2. P. 15-19. (2015).

11. A. Makarov, I. Livinsky, I. Rasskazov., B. Saksin, M. Potapchuk. JMS. 52 (3). P. 438437. (2016).

11. A.Rasskazova, T. Aleksandrova, N. Lavrik. Eurasian mining. 1, P. 25-27. (2014).

12. L. A. Samatova, E. D. Shepeta. Eurasian mining. 1. P. 33-37. (2014). 